\title{
Receptive Vocabulary Assessment in Korean-English Bilingual Children: Cross-linguistic Investigations
}

\author{
Dongsun Yim ${ }^{\mathrm{a}}$, Sara Yoon ${ }^{\mathrm{b}}$, Jiyeon Lee ${ }^{\mathrm{b}}$ \\ ${ }^{a}$ Department of Communication Disorders, Ewha Womans University, Seoul, Korea \\ ${ }^{b}$ Graduate Program in Speech Language Pathology, Ewha Womans University, Seoul, Korea
}

Correspondence: Dongsun Yim, PhD Department of Communication Disorders, Ewha Womans University, 52 Ewhayeodae-gil, Seodamun-gu, Seoul 03760, Korea

Tel: +82-2-3277-6720

Fax: +82-2-3277-2122

E-mail: sunyim@ewha.ac.kr

Received: October 6, 2014

Revised: January 28, 2016

Accepted: February 3, 2016
Objectives: Standardized tests are generally used in clinical settings in order to evaluate vocabulary size. However, this method may either overestimate or underestimate bilingual children's vocabulary skills. The present study investigates standardized tests used with Korean-English bilingual children who have a different dominant language. The purpose of the study is to examine whether social status of a language may influence bilingual children's language outcomes and to investigate the usefulness of composite scoring systems in standardized tests. Methods: Forty-two participants age 3 to 6 formed three groups: Korean-English bilinguals who speak Korean dominantly (KD-KEB), Korean-English bilinguals who speak English dominantly (ED-KEB), and monolinguals who speak Korean (K-MO). The Receptive and Expressive Vocabulary Test (REVT) and Peabody Picture Vocabulary Testfourth edition (PPVT-IV) were used; raw score and composite scoring systems were compared (within groups). Results: The raw score was significantly different from Korean-English bilingual children who are dominant in Korean and Korean-English bilingual children who are dominant in English and not significantly different from Korean-English bilingual children who are dominant in Korean and Korean speaking monolingual children. However, the three groups were not significantly different in composite scores of REVT-R and PPVT-IV. Conclusion: Standardized tests can be used to evaluate bilinguals' receptive vocabulary if composite scoring systems are applied. Thus, standardized test can be used selectively based on dominant language.

Keywords: Korean-English bilingual children, Receptive vocabulary assessment, Dominant-language
국내에서 체류하는 이민가정의 수 증가와 조기영어교육에 대한 수요가 급증하면서 한국어와 영어를 구사하는 이중언어아동 또한 점차 증가하고 있다. 이에 따라 한국어-영어 이중언어아동의 언어 발달 특성과 적절한 언어평가 및 중재에 관한 관심이 증대되고 있 다. 이중언어아동은 제 2 언어의 노출 시기에 따라 동시적 이중언어 (simultaneous bilinguals)와 순차적 이중언어(sequential bilinguals) 의 유형으로 분류된다. 동시적 이중언어아동은 출생 후 가정에서 모국어와 제 2 언어에 동시에 노출되며, 순차적 이중언어아동은 제 2 언어를 학습하기 이전에 모국어를 습득한 아동을 일컫는다(Lambert, 1977). 많은 연구자들은 두 유형의 기준을 3세 연령으로 받아 들이는데, 이 시기는 어휘와 문법체계가 대체로 확립되고 신경학적
으로도 성숙하여 제 2 언어 학습효과를 보이기 때문이다(Jia, Aaronson, \& Wu, 2002). 순차적 이중언어아동은 대개 3세경 또는 이 후에 또래나 지역사회의 구성원과 소통하거나 학업 성취를 위한 사 회적 요구에 의해 제 2 언어를 학습하는데, 연령이 증가하면서 두 언 어의 노출기간에서 차이가 발생하며 두 언어는 불균형적으로 발달 한다. 이처럼 제 2 언어의 노출시기와 노출기간은 이중언어아동의 언 어에 영향을 주는 핵심요소이며, 이러한 요소로 인해 발생하는 불 균형적 언어발달은 이중언어 아동의 자연스러운 언어특징 중 하나 이다(Grosjean, 1982; Olsson \& Sullivan, 2005; Pearson, Fernández, Lewedeg, \& Oller, 1997).

또한 이중언어아동의 언어는 아동이 사용하는 언어의 사회적 위 
치(social status)에도 영향을 받는다(Bialystok, 1991; Pearson, 2007). 이중언어아동이 구사하는 제 2 언어가 아동의 거주 지역에서 다수 언어(majority language)인지 소수언어(minority language)인지에 따라 언어의 사회적 위치는 차이가 생긴다. 다수언어는 지역사회에 서 공식적으로 인정된 언어이며, 소수언어는 소수문화에 속해있는 사람들로 구성된 지역사회에서 사용되는 언어를 의미한다(Genesee, Paradis, \& Crago, 2004). 한국과 미국의 다수언어는 각각 한국 어와 영어가 된다. 한국어-영어 이중언어아동집단 내에서도 거주 지역(예: 국가)에 따라 제 2 언어(예: 영어)의 사회적 위치의 주요한 차 이가 있다. 한국 거주 이중언어아동이 사용하는 영어의 사회적 위 치는 미국 거주 이중언어아동이 사용하는 영어의 사회적 위치보다 더 낮을 것이다. 동일한 한국어-영어 이중언어아동집단 내에서도 제2언어가 다수/소수언어인지에 따라 유창한 우세언어(dominant language)와 상대적으로 비유창한 비우세언어(non-dominant language)가 결정된다. 예를 들어, 한국 거주의 한국어-영어 이중언어 아동은 다수언어가 한국어인 사회에 속하였으므로 우세언어는 주 로 한국어인 반면, 미국 거주의 한국어-영어 이중언어아동은 다수 언어가 영어인 사회에 속하여 우세언어는 영어로 전환될 확률이 높 다. 이는 아동의 연령이 증가하면서 지역사회의 다수언어 경험에 대 한 비중이 높아지게 되어 이중언어아동의 우세/비우세 언어는 더 욱 뚜렷하게 드러난다.

이중언어아동의 언어평가 시, 아동의 우세언어와 비우세언어를 고려하여 평가언어를 선택한다. 그러나 한 언어만으로 평가를 실시 한다면 이중언어아동의 언어능력은 또래 단일언어아동에 비해 과 소평가될 수 밖에 없다(Bedore, Peña, Garcia, \& Cortez, 2005; Bialystok \& Feng, 2011). 또한 평가언어가 이중언어아동의 우세언어 와 일치하는 아동은 비우세언어와 일치하는 이중언어아동에 비해 높은 수준으로 평가될 우려가 있다. 따라서 아동에게서 어휘의 개 념(concept) 여부를 파악하기 위해서는 두 언어로 실시하여야 한 다. 즉, 이중언어아동에게 표준화 검사를 적용할 때는 하나의 언어 로 평가하여 문항 당 1점을 획득하는 원점수(raw scoring) 방식이 아닌, 두 언어로 평가한 후 최소 한 언어로 정반응을 보일 경우 문항 당 1점을 획득하는 통합점수(composite scoring) 방식을 적용한다 (Kohnert, Hernandez, \& Bates, 1998). 원점수와 통합점수 방식을 적용한다는 것은 단일언어아동의 언어검사 방식과는 구별되므로 각 채점방식을 적용한 결과를 해석할 때에도 언어발달지체를 선별 하는 과정을 넘어 우세언어 및 비우세언어를 고려하여 정보를 제시 하여야 할 것이다. 하지만 통합점수 방식은 동일한 문항을 번역하 여 제 2 언어로 다시 제시한다는 의미인데, 어휘를 번역하는 과정에 서 문항의 난이도에 주는 영향을 완전히 배제할 수 있을지 고려할
필요가 있다.

다음으로 언어평가도구 선정 시, 이중언어아동이 구사하는 두 언어를 동시에 반영하여 제작된 표준화 검사도구가 없기 때문에 한 언어권의 표준화 검사도구만으로 평가하게 되는데(Caesar \& Kohler, 2007), 이는 다른 거주 환경의 생활수준 및 문화특성을 반영하지 않는다는 한계점으로 인해 언어능력을 보다 정확히 평가하기가 어 렵다. 예를 들어, 한국어-영어 이중언어아동의 수용어휘력을 평가 하고자 국내에서 일반적으로 사용하는 수용-표현어휘력검사(Receptive and Expressive Vocabulary Test, REVT; Kim, Hong, Kim, Jang, \& Lee, 2009) 또는 영어권에서 일반적으로 사용하는 Peabody Picture Vocabulary Test fourth edition (PPVT-IV; Dunn \& Dunn, 2007)을 선택할 수 있다. 그러나 국내 임상에서는 PPVT-IV가 상용 화되어 있지 않으므로 영어권 검사도구를 사용하는데 현실적인 제 약이 따른다. 또한 이러한 표준화 검사는 해당 언어권에서 일반인 들의 연령, 성별, 지역, 생활수준을 고려하여 제작되며, 검사문항은 언어의 사용빈도, 어휘 난이도, 품사 비율, 문화 및 지역별 사용 특 성을 고려하여 구성된다. 즉, 표준화 언어검사는 다수언어문화를 중심으로 제작되었기 때문에 문화배경이 다른 소수언어 집단의 이 중언어아동에 대한 타당한 규준이 없다. 이로 인해 정상발달의 이 중언어아동을 언어발달지체로 과잉진단하는 결과를 초래한다 (Kayser, 1995; Langdon, 1992).

한국어-영어 이중언어아동들을 대상으로 한 표준화 언어검사의 타당성에 관한 의문이 제기되었으나 이에 관한 연구는 미비한 실정 이다. 선행 연구에서는 한국어-영어 이중언어아동들을 대상으로 국내 및 국외 수용어휘력검사를 실시하였는데, 연구 대상의 집단 분류를 위한 선별검사로 사용되었다(Hong \& Yim, 2014). 한국어영어 이중언어아동들에게 적용하는 표준화 검사도구의 타당성에 대한 기초연구가 필요한 실정이다. 더욱이, 한국어-영어 이중언어 아동의 우세언어는 언어경험·환경에 따라 전환되는데, 결정된 우 세언어에 따라 검사도구 선정에 영향을 주는지 검사도구 간 신뢰도 연구가 필요하며, 원점수와 통합점수 방식을 적용했을 때 두 채점 방식이 우세언어와 관련하여 어떠한 차이가 있으며, 무엇을 의미하 는지 결과해석에 대한 정보를 파악하는 것이 중요하다.

따라서 본 연구의 목적은 한국에서 거주하는 한국어 단일언어 아동집단 및 한국어-영어 이중언어아동집단, 미국에서 거주하는 한국어-영어 이중언어아동집단을 대상으로 한국어 및 영어권의 수용어휘력 검사도구를 적용하여 수행결과를 비교하고, 언어적 배 경으로 인해 우세언어가 다른 한국어-영어 이중언어아동집단 간 수용어휘력 결과를 분석함으로써 이중언어아동의 언어검사도구 결정과 평가방법, 결과해석에 대한 기초자료를 마련하고자 한다. 


\section{연구 방법}

\section{연구대상}

본 연구의 대상은 3;6-6;3 (세;개월)의 일반아동으로 성비를 맞추 어 한국에서 거주하는 한국어 우세 이중언어아동 집단, 미국에서 거주하는 영어우세 이중언어아동집단, 한국에서 거주하는 한국어 단일언어아동집단에 14 명씩 총 42 명이 참여하였다. 세 집단의 아 동들은 (1) 부모설문지(Alberta Language and Development Questionnaire, ALDeQ; Paradis, Emmerzael, \& Duncan, 2010) 결과에 서 신체발달 및 언어발달이 -1 SD 이상으로 정상범주에 속하거나 Korea Kaufman Assessment Battery for Children (K-ABC; Moon \& Byun, 2003)의 동작성 지능검사의 표준점수가 85점 이상으로 (2) 부모, 교사의 보고에 의해 신체적, 감각적, 정서적, 언어적, 정서 적 문제를 보이지 않는다고 보고되었으며 (3) 장애진단기록이 없고 언어치료나 기타 재활서비스를 받은 경험이 없는 아동들을 대상으 로 선정하였다. 각 연령별 이중언어아동 및 단일언어아동에 대한 대상자 정보는 Table 1 에 제시되어 있다.

이중언어아동집단은 모국어가 한국어로 가정에서 부모님과 모 국어를 사용하며, 제 2 언어가 영어인 이중언어 아동들로 학교에서 영어를 사용하는 아동으로 선정하였으며(Kohnert, 2008) 연구에 참여한 이중언어 아동들은 영어권 국가에서 최소 2 년 이상 생활하 였거나 영어교육기관에서 최소 2년 이상 교육을 받은 아동으로 하 루에 5 시간 이상 원어민의 영어로 학습, 놀이 수업, 쉬는 시간 또는 일상생활에서 노출되어 생활하는 아동들이었다(Hong \& Yim, 2014). 영어우세 이중언어아동집단은 미국 LA에서 거주하는 이민 2세 가정의 아동들로 가정에서 부모님과 한국어를 모국어로 사용 하며, 사회언어가 영어인 환경에 놓여있어 학교에서 영어를 사용하 는 아동이었고, 한국어우세 이중언어아동집단은 한국 서울·경기

Table 1. Descriptive information of participants: chronological age, LOR, dominant language, $\mathrm{ALDeO}$ and gender ratio

\begin{tabular}{lccc}
\hline & ED-KEB $(n=14)$ & KD-KEB $(n=14)$ & K-MO $(n=14)$ \\
\hline Chronological age (mo) & $52(7)$ & $65(5)$ & $51(6)$ \\
LOR (mo) & $42(13)$ & $34.07(6)$ & - \\
Dominant language & English & Korean & Korean \\
ALDe0 & $>-1$ SD & $>-1$ SD & $>-1$ SD \\
K-ABC & $>85$ & $>85$ & $>85$ \\
Gender (male:female) & $6: 8$ & $6: 8$ & $6: 8$ \\
\hline
\end{tabular}

Values are presented as mean (SD) or number

$\mathrm{LOR}=$ length of residence; $\mathrm{ED}-\mathrm{KEB}=$ Korean-English bilinguals who speak English dominantly; KD-KEB=Korean-English bilinguals who speak Korean dominantly; K$\mathrm{MO}=$ monolinguals who speak Korean; $\mathrm{ALDeO}=$ Alberta Language and Development Questionnaire (Paradis, Emmerzael, \& Duncan, 2010); K-ABC= Korea Kaufman Assessment Battery for Children (Moon \& Byun, 2003).
에 거주하는 아동들로 사회언어가 한국어인 환경에 놓여있는 아 동들이었다. 대상자들의 부모는 한국어만을 구사하거나 한국어와 영어를 동시에 구사하였고, 최종학력은 고졸 이상이었다. 이중언어 아동들은 부모와 상호작용 시 한국어를 사용하지만, 형제 및 또래 와는 한국어와 영어를 사용한다고 보고하였다. 단일언어집단은 (1) 국내 이중언어아동집단과 동일한 지역에 거주하는 아동으로, (2) 한국에서 출생하였고 외국에서 거주한 경험이 없으며, (3) 대화상 대자와 한국어로 소통하고, (4) 영어노출시간이 하루에 1 시간 미만 이었다.

각 집단 간 연령 및 영어노출기간에 유의한 차이가 있는지 살펴 보기 위해 일원분산분석(one-way ANOVA)을 실시하였다. 분석 결 과, 연령에서 집단간차이가 통계적으로 유의하였으며 $\left(F_{(2,39)}=21.393\right.$, $p<.01)$ Scheffe 사후검정 결과, 영어우세 이중언어아동집단과 단일 언어아동집단의 연령이 한국어우세 이중언어아동집단에 비해 유 의하게 낮았으며, 영어우세 이중언어아동집단과 단일언어아동집 단 간 연령에서는 유의한 차이가 없었다. 영어노출기간에서 집단 간 차이가 통계적으로 유의하였으며 $\left(F_{(1,26)}=4.365, p<.05\right)$, 영어우 세 이중언어아동집단의 영어노출기간이 한국어우세 이중언어아 동집단보다 유의하게 더 길었다.

\section{검사도구 및 절차}

\section{선별도구}

모국어 발달을 평가하기 위하여 부모설문(ALDeQ; Paradis et al., 2010)을 실시하였다. 설문지의 문항은 4 개의 영역으로 나뉘었고 초기 발달단계, 현재 모국어능력, 좋아하는 행동이나 활동, 가족력 에 대한 영역으로 구성되어 있다. 설문지는 특정 언어나 문화집단 을 위해서 고안되지 않았으며, 부모님이 한국어로 작성된 문항에 대해서 이해하지 못할 경우 통역을 하거나 영문으로 함께 제시하였 다. 평가결과 $-1.5 \mathrm{SD}$ 미만에 속하는 아동을 제외하였다.

이중언어아동집단을 대상으로 $\mathrm{K}-\mathrm{ABC}$ 교육·심리측정도구(K$\mathrm{ABC} ;$ Moon \& Byun, 2003)의 동작성 지능검사를 한국어 또는 영 어로 실시하여 표준점수 85점 이상에 속하는 아동을 선별하였고, 본 검사는 만 4 세부터 12 세까지 적용할 수 있는 검사이므로 대상 연령에 포함되지 않은 아동일 경우 부모설문지 결과로 대체하였다. 설문조사 또는 K-ABC 검사 결과, 모든 대상 아동들은 연구자의 지 시를 이해하고 수행하는 데 충분한 인지, 언어, 운동 수준을 갖추었 음을 확인하였다.

\section{본 검사도구}

한국어-영어 이중언어아동의 수용어휘능력을 평가하기 위한 표 
준화 검사도구가 없기 때문에 각 언어권에서 사용하는 수용어휘력 검사도구를 기존의 방식과 다른 방법으로 실시하였다. 한국어 수 용어휘력을 평가하기 위해 수용·표현어휘력검사(REVT; Kim et al., 2009)에서 수용어휘력검사(REVT-R)를 사용하였고, 영어 수용 어휘능력을 평가하고자 Peabody Picture Vocabulary Test-fourth edition (PPVT-IV; Dunn \& Dunn, 2007)을 사용하였다. 두 검사과 정에서 연구자는 아동에게 지시사항과 단어, 피드백을 구어로 제 시하되 REVT-R에서는 한국어로, PPVT-IV에서는 영어를 사용하 였고 아동은 네 개의 그림 중 해당되는 하나의 그림을 선택하였다.

수용어휘력 평가절차는 다음과 같다. 본 표준화검사는 이중언 어 아동을 대상으로 하지 않았기 때문에 시작 문항을 기존의 방식 과 차이를 두어 연령에 관계없이 1 번 문항부터 시작하였다. 각 검사 당 2 회씩 평가하였으며, 1 차 평가에서는 검사도구의 주류문화에 해당하는 평가언어(또는 사회언어)로 실시하였고, 2 차 평가는 1 차 평가에서 오반응을 보인 문항에 대해 비평가언어로 재실시하였다. 이를 통해 단어-개념의 연관성의 습득 여부를 알아보고자 하였다.

각 검사도구의 기초선과 최고한계선의 기준은 표준화 방식에 따 라 설정하였다. REVT-R의 기초선은 연속으로 8 개 문항을 맞출 경 우이며, 최고한계선은 8 개 문항 중 6 개를 틀릴 경우로 설정하였다. 예를 들어, REVT-R에서 한국어로 문항을 들려주어 반응을 이끌 어낸 후 연속 8 개를 맞추면 기초선으로 설정하였고, 8 개 중 6 개 이 상 틀리면 중단한 뒤 기초선 이후 문항 중 오반응을 보였던 첫 문항 으로 돌아가 영어로 다시 들려주었다. 오반응 문항에 대해 다시 묻 는 과정이 아동에게 단서를 주어 정확도를 높일 것을 감안하여 정 반응을 보였던 일부 문항에 대해서도 재확인하였다. 이와 같이 평 가언어와 비평가언어로 연속 8 개 문항에서 정반응을 보이면 기초 선으로 확립하였고, 8 개 중 6 개 이상의 문항을 평가언어(예; 한국 어)와 비평가언어(예; 영어)로 모두 틀릴 경우 최고한계선으로 간주 하여 검사를 중단하였다. PPVT-IV의 문항은 총 19 개 세트로, 세트 당 12 개 문항으로 구성되어 있는데, 기초선은 한 세트 내에서 한 개 이하의 오반응을 보일 경우이며, 최고한계선은 한 세트 내에서 8 개 이상의 오반응을 보일 경우로 검사지침대로 설정하였다. 실시과정

Table 2. Descriptive statistics of REVT-R score by groups

\begin{tabular}{lccc}
\hline & ED-KEB $(n=14)$ & KD-KEB $(n=14)$ & K-MO $(n=14)$ \\
\hline Raw score (SD) & $25.79(12.87)$ & $61.21(6.92)$ & $48.14(9.01)$ \\
Composite score (SD) & $55.21(15.90)$ & $72.07(12.39)$ & - \\
\hline
\end{tabular}

Values are presented as mean (SD).

$\mathrm{ED}-\mathrm{KEB}=$ Korean-English bilinguals who speak English dominantly; $\mathrm{KD}-\mathrm{KEB}=$ KoreanEnglish bilinguals who speak Korean dominantly; $\mathrm{K}-\mathrm{MO}=$ monolinguals who speak Korean; REVT-R=Receptive \& Expressive Vocabulary Test-receptive.
은 REVT와 동일한 방법으로 평가언어(예: 영어)로 1차 검사를 실 시한 후, 비평가언어(예: 한국어)로 재검사하였다.

\section{자료분석}

원점수, 통합점수와 두 언어에 대한 의존도

원점수는 1 차 검사 시 평가언어로 실시한 정반응 문항수이며 통 합점수는 2 차 검사 후 평가언어 및 비평가언어에 대해 정반응을 보 인 문항수를 합한 총점으로 산출하였다. 원점수는 기존 방식으로 한 언어로 제시하여 정반응을 보이면 1점, 오반응을 보이면 0점으 로 계산한다. 통합점수는 어휘의 개념을 확인하는 채점방식으로 서, 평가언어 또는 비평가언어에서 정반응을 하면 1점을 획득할 수 있다. 이중언어아동 집단의 경우 REVT-R, PPVT-IV의 원점수와 통합점수를 수집하였고, 단일언어집단은 한국 아동만을 대상으로 하였으므로 REVT의 원점수를 수집하여 비교, 분석하였다.

두 언어에 대한 의존도는 집단별 원점수 대비 통합점수 비율로 조작적 정의를 하였으며, 각 검사도구에서 우세언어에 의존하는 정 도를 살펴보기 위하여 산출하였다.

\section{자료의 통계분석}

수집된 자료들은 SPSS 19.0 프로그램을 이용하여 분석하였으며, 검사도구 및 채점방식에 따른 집단 간 수용어휘력 점수의 차이를 알아보기 위하여 연령을 공변량으로 한 공분산분석(ANCOVA)과 이원혼합분산분석(two-way mixed ANOVA)을 실시하였다.

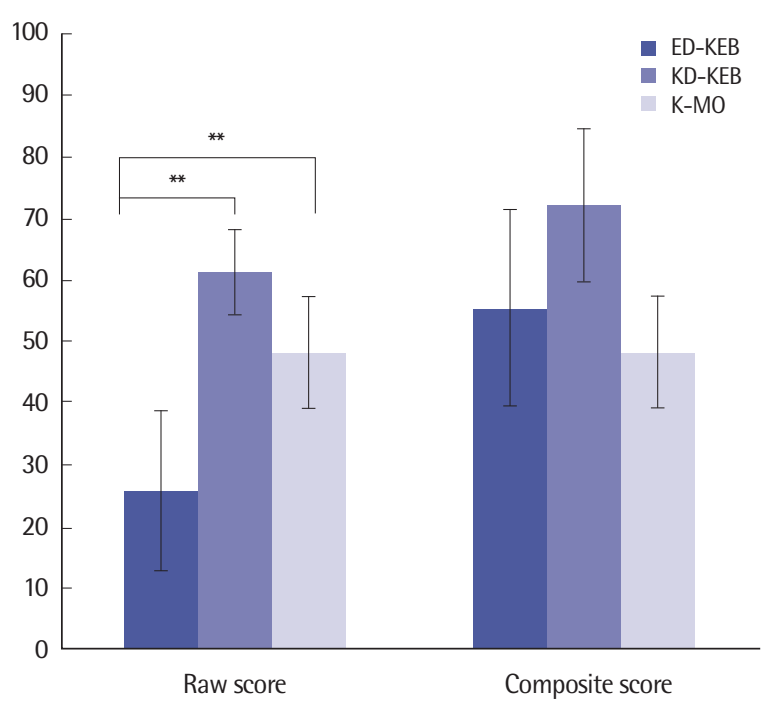

Figure 1. The raw scores and composite scores in REVT-R. ED-KEB=KoreanEnglish bilinguals who speak English dominantly; KD-KEB=Korean-English bilinguals who speak Korean dominantly; K-MO=monolinguals who speak Korean; REVT-R=Receptive \& Expressive Vocabulary Test-receptive. ${ }^{* *} p<.01$. 


\section{연구 결과}

\section{세 집단 간 수용어휘력 검사 점수}

연령에서 집단 간 차이가 통계적으로 유의하였으므로 연령을 공 변량으로 통제하여 REVT-R의 원점수 및 통합점수를 변수로 공분 산분석(ANCOVA)을 실시하였다. 영어우세 이중언어아동집단, 한 국어우세 이중언어아동집단, 한국어 단일언어집단의 REVT-R 원 점수 및 통합점수에 대한 기술통계와 그래프는 각각 Table 2, Figure 1 과 같다. 그 결과, 세 집단 간 REVT-R의 원점수 차이가 통계적 으로 유의하였다 $\left(F_{(2,38)}=35.692, p<.01\right)$. Bonferroni 사후검정 결 과, 영어우세 이중언어아동집단의 원점수가 한국어우세 이중언어 아동집단과 단일언어집단보다 유의하게 낮았으나 한국어우세 이 중언어아동집단의 원점수는 단일언어집단과 차이가 통계적으로 유의하지 않았다. 세 집단 간 REVT-R의 통합점수 차이가 통계적 으로 유의하지 않았다 $\left(F_{(2,38)}=1.987, p>.05\right)$.

\section{이중언어아동 집단 간 REVT-R 및 PPVT-IV의 원점수 및 통합점수 비교}

REVT-R과 PPVT-IV 검사도구에서 채점방식에 따른 이중언어 아동집단 간 차이를 살펴보기 위하여 연령을 공변량으로 통제하 여 이원혼합분산분석(two-way mixed ANOVA)을 실시하였다. REVT-R의 결과는 Figure 2에 제시하였다. 집단에 대한 주효과가 유의하였으며 $\left(F_{(1,25)}=7.30, p<.05\right)$, 한국어우세 이중언어아동집단 의 점수평균 $(\mathrm{M}=59.72)$ 이 영어우세 이중언어아동집단 $(\mathrm{M}=47.42)$ 보다 유의하게 높았다. 채점방식에 대한 주효과가 통계적으로 유의 하지 않았다 $\left(F_{(1,25)}=.552, p>.05\right)$. 집단 $\times$ 채점방식의 상호작용이 통계적으로 유의하였다 $\left(F_{(1,25)}=6.062, p<.05\right)$. 사후검정을 실시한

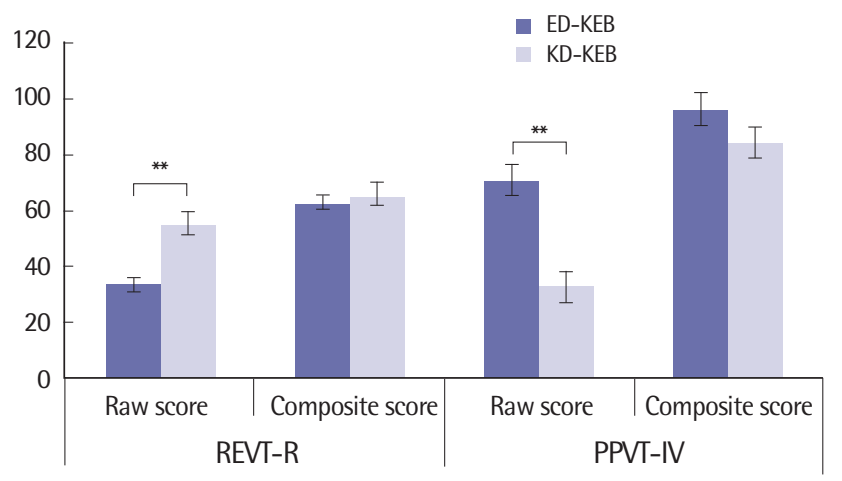

Figure 2. The raw scores and composite scores in PPVT-IV and REVT-R. ED-KEB= Korean-English bilinguals who speak English dominantly; KD-KEB =KoreanEnglish bilinguals who speak Korean dominantly; REVT-R=Receptive \& Expressive Vocabulary Test-receptive; PPVT-IV = Peabody Picture Vocabulary Testfourth edition. ${ }^{* *} p<.01$.
결과, 한국어우세 이중언어아동집단의 원점수 $(\mathrm{M}=61.21)$ 가 영어 우세 이중언어아동집단 $(\mathrm{M}=25.79)$ 보다 유의하게 큰 반면 $\left(F_{(1,25)}=\right.$ $24.037, p<.01)$, 통합점수에서는 집단 간 차이가 유의하지 않았다 $\left(F_{(1,25)}=.155, p>\right.$.05). PPVT-IV에서 채점방식에 따른 이중언어아동 집단 간 차이를 분석한 결과는 Figure 2에 제시하였다. 집단에 대한 주효과가 통계적으로 유의하였다 $\left(F_{(1,25)}=9.012, p<.05\right)$. 영어우세 이중언어아동집단의 점수평균 $(\mathrm{M}=82.889)$ 이 한국어우세 이중언 어아동집단 $(M=57.861)$ 보다 유의하게 높았다. 채점방식에 대한 주 효과가 통계적으로 유의하지 않았다 $\left(F_{(1,25)}=.163, p>.05\right)$. 집단 $\times$ 채점방식의 상호작용이 통계적으로 유의하였다 $\left(F_{(1,25)}=11.917\right.$, $p<.05)$. 사후검정을 실시한 결과, 영어우세 이중언어아동집단의 원점수 $(\mathrm{M}=12.87)$ 가 한국어우세 이중언어아동집단 $(\mathrm{M}=6.92)$ 보 다 유의하게 큰 반면 $\left(F_{(1,25)}=17.060, p<.01\right)$, 통합점수에서는 집단 간 차이가 유의하지 않았다 $\left(F_{(1,25)}=1.695, p>.05\right)$.

\section{REVT-R 및 PPVT-IV에서의 이중언어아동집단 간 두 언어에 대한 의존도}

REVT-R과 PPVT-IV에서 두 집단 간 원점수 대비 통합점수의 비 율을 구하여 두 언어에 대한 의존도(\%)를 확인하기 위하여 연령을 공변량으로 통제하여 이원분산분석을 실시하였다. 그 결과, REVT$\mathrm{R}$ 의 한국어 의존도에서 집단 간 차이가 통계적으로 유의하였다 $\left(F_{(1,24)}=7.291, p<.05\right)$. 한국어우세 이중언어아동집단의 한국어 의 존도 평균 $(\mathrm{M}=83.10)$ 이 영어우세 이중언어아동집단의 한국어 의 존도 평균(M=51.80)보다 유의하게 높았다. PPVT-IV의 영어 의존 도에서 집단간차이가 통계적으로 유의하였다 $\left(F_{(1,24)}=14.117, p<.01\right)$. 영어우세 이중언어아동집단의 영어 의존도 평균( $\mathrm{M}=74.50)$ 이 한 국어우세 이중언어아동집단의 영어 의존도 평균 $(\mathrm{M}=42.40)$ 보다

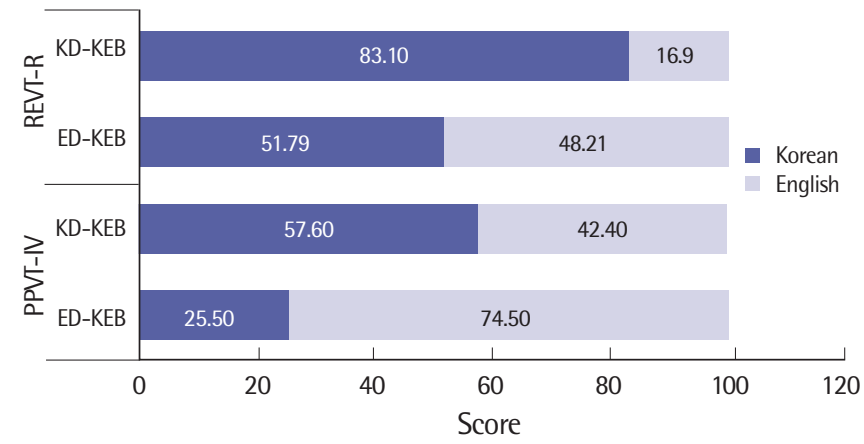

Figure 3. The ratio of dominant language in REVT-R and PPVT-IV. ED-KEB= Korean-English bilinguals who speak English dominantly; KD-KEB=KoreanEnglish bilinguals who speak Korean dominantly; REVT-R=Receptive \& Expressive Vocabulary Test-receptive; PPVT-IV = Peabody Picture Vocabulary Testfourth edition. 
유의하게 높았다. 언어평가도구별 우세언어 의존도를 나타낸 결과 를 Figure 3 에 제시하였다.

\section{논의 및 결론}

본 연구는 우세언어가 다른 한국어-영어 이중언어아동집단을 위한수용어휘력 검사도구의 적용가능성을 확인하고자 한국어 단 일언어아동집단과 비교하여 연구를 실시하였다. 이를 위하여 총 42 명을 대상으로 REVT-R과 PPVT-IV를 이용하여 수용어휘력을 측 정하였고, 1 차 검사는 단일언어로 실시하여 원점수를 산출하였고 2차 검사는 두 언어로 실시하여 통합점수를 산출하였다.

연구 결과, 첫째, REVT-R에서 한국어만으로 평가한 경우 한국 어우세 이중언어아동집단과 단일언어아동집단의 원점수가 영어 우세 이중언어아동집단보다 높았으나 한국어우세 이중언어아동 집단과 단일언어집단 간 차이는 유의하지 않았다. 그러나 한국어와 영어로 평가한 경우, 한국어우세 이중언어아동집단과 영어우세 이 중언어아동집단의 통합점수는 단일언어아동 집단의 원점수와 차 이가 유의하지 않았다. 이 결과는 이중언어아동집단에게 두 언어 로 평가를 실시하여야 단일언어집단의 규준과 비교가능하며 보다 적절한 정보를 얻을 수 있다는 선행연구 결과와 일치한다(Core, Hoff, Rumiche, \& Señor, 2013). 또한 한국어우세 이중언어아동집 단과 단일언어아동집단 간 원점수의 차이가 유의하지 않은 것은 한국어우세 이중언어아동집단이더라도 영어 노출의 양이 전체 어 휘크기에 영향을 줄 만큼 그리 많지 않았던 것으로 생각하며, 이중 언어 중 한 언어입력의 양이 전체 언어입력의 양의 절반 이상이 될 때, 표준화검사에서 잘못 평가될 위험이 거의 없다는 선행연구의 결과와부분 일치한다(Thordardottir, 2008).

둘째, REVT-R과 PPVT-IV의 통합점수에서 영어우세 이중언어 아동집단과 한국어우세 이중언어아동집단 간 유의한 차이가 나타 나지 않았으나 원점수에서 유의한 차이가 나타났다. REVT-R에서 는 한국어우세 이중언어아동집단의 원점수가 영어우세 이중언어 아동집단보다 높았으며, PPVT-IV에서는 영어우세 이중언어아동 집단의 원점수가 한국어우세 이중언어아동집단보다 높았다. 즉, 동 일한 한국어-영어 이중언어아동집단에게 통합점수 비교가 전체 어 휘크기를 확인할 수 있는 과정이라면, 원점수의 비교는 우세언어에 대한 정보를 제공하는 데 효과적이라고 할 수 있겠다.

셋째, 이중언어아동집단 간 수용어휘력 평가 시 두 언어의 의존 도를 비교한 결과, REVT-R에서 영어우세 이중언어아동의 영어 의 존도는 52\%였으며 PPVT-IV에서 한국어우세 이중언어아동의 한 국어 의존도는 $58 \%$ 인 것으로 나타났다. 이러한 결과는 이중언어아
동의 수용어휘력 평가를 두 언어로 실시하지 않는다면, 즉, 언어평 가 시 $50 \%$ 이상 우세언어에 의존하므로 비우세언어만으로 어휘를 평가한다면 아동들의 전체 어휘크기의 상당 부분을 저평가할 우려 가 있음을 시사한다. 반대로 우세언어만으로 평가를 하게 될 경우 비우세언어만으로 학습한 어휘량을 놓칠 우려가 있기 때문에 반드 시 두 언어로 어휘를 평가하여야 보다 정확한 어휘크기를 파악할 수 있을 것이다. 연구결과 중 흥미로웠던 것은 이중언어아동집단의 우세언어에 기초한 평가도구를 실시하였을 때, 이중언어아동의 비 우세언어 의존도이다. REVT-R에서 한국어우세 이중언어아동집 단의 영어 의존도는 $17 \%$ 였고, PPVT-IV에서 영어우세 이중언어아 동집단의 한국어 의존도는 $25 \%$ 였다. 앞서 단일언어집단과 한국어 우세 이중언어아동집단 간 REVT-R 원점수의 차이가 유의하지 않 았다고 하였으나 기술통계적으로 한국어우세 이중언어아동집단 의 수용어휘 크기 중 $17 \%$ 가 영어노출에 의한 어휘습득인 것으로 볼 수 있다. 본 연구대상인 한국어우세 이중언어아동집단은 학령 전기의 아동이므로 만약 이 아동들이 학령기가 되어 국제학교 입 학 또는 유학 등의 이유로 제 2 언어의 노출량이 증가한다면, 영어 의 존도가 상대적으로 높아지거나 우세언어가 영어로 전환될 수 있기 때문에 단일언어아동집단과 REVT-R의 원점수 비교가 어려울 것 이다. 반면, 미국에서 거주하는 한국어-영어 이중언어아동집단 즉, 영어우세 이중언어아동들이 국내로 귀국하여 장기간 정착한다면 그들의 우세언어도 한국어로 전환될 수 있음을 의미한다.

이러한 결과들은 이중언어아동들의 수용어휘력 평가 시, 모국어 와 제 2 언어인 두 언어로 실시하여야 단일언어아동집단과의 비교 결과를 보다 신뢰할 수 있음을 시사한다. 우세언어를 파악하고 수 용 어휘크기에 대한 정보를 구체적으로 파악하기 위해서는 원점수, 통합점수의 채점방식으로 두 언어권에 기초한 언어검사도구들을 모두 사용하여 평가할 수 있다. 그러나 소요시간이 길어지며, 언어 평가는 단지 수용어휘력 평가만으로 그치지 않기 때문에 효율성을 고려해야 한다면, 우세언어에 기초한 평가도구를 선택적으로 사용 하되 반드시 두 가지 채점방식을 사용할 것을 권한다. 또한, 이중언 어아동을 위한 규준이 마련되어 있지 않으므로 보다 정확한 언어 평가를 위해 표준화검사뿐만 아니라 부모설문과 같은 비표준화 평 가도구가 포함되어야 할 것이다. 더불어 임상가의 제 2 언어능력과 다양한 문화권에 대한 지식 이해가 요구될 것이다.

본 연구의 영어우세 이중언어아동집단은 미국에서 거주하는 아 동이었으나 국내에서도 한국어우세였던 이중언어아동이 국제학 교 입학 또는 조기유학 등 언어환경의 변화로 인해 영어우세로 전 환될 가능성이 있으므로 이에 대한 기초자료로 활용할 수 있을 것 으로 보인다. 그러나 본 연구는 언어발달지체가 없는 학령전기의 일 
반아동들을 대상으로 이루어졌으며 전체 한국어-영어 이중언어아 동집단을 해석하여 일반화하기에 제한적이다. 따라서 대상자 수를 충분히 확보하여 언어발달지체 이중언어아동을 선별하기 위한 평 가적용에 대한 후속연구가 이루어질 것을 기대한다. 또한 한국어 이중언어아동들의 REVT-R의 원점수가 단일언어아동집단보다 유 의미하지는 않지만 더 높았던 점은 초기 어휘발달에 영향을 줄 수 있는 외부요인(예; 부모 학력, 경제적 수준, 사회경제적 지위 등)에 대한 통제가 이뤄지지 않았던 점으로 생각된다. 나아가 변인을 보 다 통제하고, 종단연구를 통해 학령기 이중언어아동들의 우세언어 의존도 변화 및 이해, 표현어휘 양상을 살펴볼 필요가 있다.

\section{REFERENCES}

Bedore, L. M., Peña, E. D., Garcia, M., \& Cortez, C. (2005). Conceptual versus monolingual scoring: when does it make a difference? Language, Speech, and Hearing Services in Schools, 36, 188-200.

Bialystok, E. (1991). Language processing in bilingual children. Cambridge: Cambridge University Press.

Bialystok, E., \& Feng, X. (2011). Language proficiency and its implications for monolingual and bilingual children. In A. Y. Durgunoglu \& C. Goldenberg (Eds.), Language and literacy development in bilingual settings (pp. 121-138). New York, NY: Guilford Press.

Caesar, L. G., \& Kohler, P. D. (2007). The state of school-based bilingual assessment: actual practice versus recommended guidelines. Language, Speech, and Hearing Services in Schools, 38, 190-200.

Core, C., Hoff, E., Rumiche, R., \& Señor, M. (2013). Total and conceptual vocabulary in Spanish-English bilinguals from 22 to 30 months: implications for assessment. Journal of Speech, Language, and Hearing Research, 56, 16371649.

Dunn, L. M., \& Dunn, D. M. (2007). PPVT-4: Peabody: Picture Vocabulary Test (4th ed.). Bloomington, MN: Pearson Assessments.

Genesee, F., Paradis, J., \& Crago, M. B. (2004). Dual language development \& disorders: a handbook on bilingualism \& second language learning (v. 11). Baltimore, MD: Paul H. Brookes Publishing.

Grosjean, F. (1982). Life with two languages: an introduction to bilingualism. Cambridge, MA: Harvard University Press.

Hong, S., \& Yim, D. (2014). The assessment of language impairment in bilingual children through learning and memory tasks. Communication Science \& Disorders, 19, 31-44.

Jia, G., Aaronson, D., \& Wu, Y. (2002). Long-term language attainment of bi- lingual immigrants: predictive variables and language group differences. Applied Psycholinguistics, 23, 599-621.

Kayser, H. (1995). Assessment of speech and language impairments in bilingual children. In H. Kayser (Ed.), Bilingual speech-language pathology: an Hispanic focus (pp. 243-264). Clifton Park, NY: Delmar, Cengage Learning.

Kim, Y. T., Hong, G. H., Kim, K. H., Jang, H. S., \& Lee, J. Y. (2009). Receptive \& expressive vocabulary test (REVT). Seoul: Seoul Community Rehabilitation Center.

Kohnert, K. J., Hernandez, A. E., \& Bates, E. (1998). Bilingual performance on the Boston Naming Test: preliminary norms in Spanish and English. Brain and Language, 65, 422-440.

Kohnert, K. (2008). Language disorders in bilingual children and adults. San Diego, CA: Plural.

Lambert, W. E. (1977). The effects of bilingualism on the individual: cognitive and sociocultural consequences. In P. A. Hornby (Ed.), Bilingualism: psychological, social, and educational implications (pp. 15-27). New York, NY: Academic Press.

Langdon, H. W. (1992). Speech and language assessment of LEP/bilingual Hispanic students. In H. W. Langdon \& L. Cheng (Eds.), Hispanic children and adults with communication disorders (pp. 201-271). Gaithersburg, MD: Aspen Publishers.

Moon, S. B., \& Byun, C. J. (2003). Korean Kaufman assessment battery for children $(K-A B C)$. Seoul: Hakjisa.

Olsson, Å., \& Sullivan, K. P. (2005). Provoking dominance shift in a bilingual Swedish-American English 4-year-old child. In J. Cohen, et al. (Eds.), Proceedings of the 4th International Symposium on Bilingualism (pp. 1750-1764). Somerville, MA: Cascadilla Press.

Paradis, J., Emmerzael, K., \& Duncan, T. S. (2010). Assessment of English language learners: using parent report on first language development. Journal of Communication Disorders, 43, 474-497.

Pearson, B. Z. (2007). Social factors in childhood bilingualism in the United States. Applied Psycholinguistics, 28, 399-410.

Pearson, B. Z., Fernández, S. C., Lewedeg, V., \& Oller, D. K. (1997). The relation of input factors to lexical learning by bilingual infants. Applied Psycholinguistics, 18, 41-58.

Thordardottir, E. (2008). Relationship between amount of language exposure and language scores in older preschool children acquiring French and English simultaneously. Paper presented at the Congress of the International Association for the Study of Child Language, University of Edinburgh, Edinburgh, UK. 


\section{국문초록}

\section{교차언어 연구를 통한 한국어-영어 이중언어아동의 수용어휘력 평가}

임동선 $\cdot$ 윤사라 $\cdot$ 이지연 2

${ }^{1}$ 이화여자대학교 언어병리학과, ${ }^{2}$ 이화여자대학교 대학원 언어병리학과

배경 및 목적: 이중언어아동의 어휘 평가 시, 일반적으로 단일언어아동을 대상으로 제작된 표준화 검사도구를 사용한다. 그러나 이중 언어아동이 사용하는 두 언어 중 한 언어만을 평가한다면, 언어능력을 과소평가하여 언어장애로 과잉 진단할 우려가 있다. 이중언어아 동의 연령 증가와 언어경험의 변화를 겪으면서 우세/비우세 언어가 전환될 수 있는데, 두 언어권의 검사도구에 대한 적용이 가능한 상 황에서 우세언어에 따라 검사도구 선택에 영향을 주는지, 검사결과를 통해 우세언어를 파악할 수 있는지를 알아보고자 하였다. 방법: 42명의 만 3-6세 아동들(단일언어 vs. 한국어우세 이중언어 vs. 영어우세 이중언어)을 대상으로 수용어휘력 검사 REVT-R과 PPVT-IV 를 실시하여 원점수 및 통합점수를 비교하였다. 통계처리는 공변량 분산분석, 이원혼합분산분석을 사용하였다. 결과: 수용어휘력검사 에서 한국어만으로 평가한 경우, 한국어우세 이중언어아동집단과 단일언어아동집단의 원점수가 영어우세 이중언어아동집단보다 높 았으나 한국어우세 이중언어아동집단과 단일언어집단 간 차이는 유의하지 않았다. 그러나 한국어와 영어로 평가한 경우, 한국어우세 이중언어아동집단과 영어우세 이중언어아동집단의 통합점수는 단일언어아동집단의 원점수와 차이가 유의하지 않았다. 따라서 통합 점수 방식은 이중언어아동의 수용어휘력을 적절히 평가할 수 있었으며, 우세언어 및 비우세언어에 대한 구체적인 정보를 확인 또한 가 능하게 하였다. 논의 및 결론: 이중언어아동의 수용어휘력 평가를 위해 표준화된 언어평가도구의 적용이 가능하지만 우세언어와 비우 세언어를 제시하여 종합적으로 평가해야 하며, 우세언어에 따라 두 언어권에 해당되는 검사도구 중 선택적으로 사용할 수 있다.

핵심어: 한국어-영어 이중언어아동, 수용어휘력 평가, 우세언어

\section{참고문헌}

김영태, 홍경훈, 김경희, 장혜성, 이주연(2009). 수용·표현어휘력검사(REVT). 서울: 서울장애인종합복지관.

문수백, 변창진(2003). K-ABC 교육·심리측정도구(K-ABC). 서울: 학지사.

홍성미, 임동선(2014). 학습 및 기억과제를 통한 이중언어아동의 언어발달지체 평가. 언어청각장애연구, 19, 31-44. 